\title{
Kindhearted Inspector in Pursuit of Motives and Truth
}

\section{The Safety Net. By Andrea Camilleri; Penguin Books (Imprint of Penguin Random House, LLC); New York, New York; 2020; ISBN 9780143134961; pp 255; \$ 16 (paperback)}

\author{
Richard Balon ${ }^{1}$ (1) \\ Received: 4 August 2020 / Accepted: 17 August 2020 / Published online: 28 August 2020 \\ (C) Academic Psychiatry 2020
}

One of my friends suggested to me recently that I should write another Literary Column about a mystery book. Thinking of it, I realized that though the editors decided to include an occasional mystery review in Academic Psychiatry, the journal has not published one since 2015 [1]. And, as I was coincidentally reading the latest mystery by Andrea Camilleri, I felt that reviewing it would be a nice tribute to Camilleri's writing, as, unfortunately, Camilleri died recently. I also thought that it would be fitting to introduce his work and the interesting character Detective Inspector Montalbano to those who like me need some relaxing reading during these trying times.

The story in Safety Net involves two investigations, led by Inspector Salvo Montalbano and his police department in a fictitious Sicilian city of Vigata, modeled on Camilleri's hometown of Porto Empedocle. The first investigation is focused on a shooting in the local school, possibly related to the bullying of a computer whiz kid. The other one is a favor to a local engineer, who would like to figure out why his father shot an old super 8-mm amateur movie six times between 1958 and 1963, always on the same day and at the same hour and of the same part of a wall. Both these investigations happen while, to Montalbano's displeasure, a Swedish-Italian movie crew is making a 1950 s style movie in present-day Vigata.

Montalbano immerses himself into both investigations in his typical style, which may seem haphazard. He questions witnesses and sends out his deputies but also collects information while dining in his favorite restaurant and chatting with old patrons (Montalbano loves to eat, both in restaurants and at home, where his housekeeper, Adelina, prepares him

Richard Balon

rbalon@wayne.edu

1 Wayne State University, Detroit, MI, USA delicious dishes). His investigations progress in a way that is hard for others to understand. He may dream about related issues or have debates with his girlfriend, Livia, who lives far away in Genoa, on the Italian mainland, or he employs the skills of a seemingly dull desk policeman who works for him. Montalbano knows his city and his people. He frequently veers into psychological and even philosophical discourses in his debates with witnesses and colleagues.

Montalbano is always attempting to understand others' motives. For instance, he says to the math teacher who denies a role in the school shooting because he has "no enemies," "Personal convictions are never enough for me. I need to know, beyond your impressions" and adds, "I don't think there's single man alive who can say he doesn't have any enemies. I'll grant you that the word 'enemy' may be a bit excessive. But it's impossible for a man not to know a single person he might rub the wrong way, and who detests him for one reason or another, or maybe envies him" (p. 146). He continues, "Nowadays, in a world as neurotic as ours, all it takes is the slightest thing to set a person off. How often have we read in the papers about situations, say, where someone steals someone else's parking spot, and the guy who feels cheated can't help but get out of the car and beat the other person to death?"' (p. 147).

During the investigation of the school shooting, Montalbano tries to understand the world of teenagers. He notices that they, scattered around a café, are together but very isolated, seemingly hypnotized, never raising their heads to look at each other, all having the same posture: "Chin resting on the chest, elbows tucked tightly into the waist, both hands squeezing something they were caressing with their thumbs, the only part of their bodies that was moving" (p. 154). They all have pinpoint pupils and look lost to him. He mused about how it was "possible, in the age of global communication, where all cultural, linguistic, geographical, and economic borders had been erased from the face of the earth, that this vast new realm had only created a multitude of loners, infinite 
numbers of lonely people in communication with one another, yes, but still in a state of utter solitude" (p. 155).

Montalbano ultimately figures out both mysteries. (I am not going to spoil the book for those who I hope might decide to read it.) The strange yearly movie shots related to the death of a twin brother of the man who made these movies, who suffered from autism and to whom his brother was a sort of protective, loving father. And yes, the shooting in the school was related to bullying, but in a quite complex way.

As the reader can probably guess, Inspector Montalbano and Sicily are the two main characters of this book and of all Camilleri's series of Montalbano books. Montalbano is a sympathetic cop who cannot stay out of trouble with the authorities, yet he gets out of difficulties by being able to solve cases. He is a funny, sardonic observer of the world. He became very popular in Europe; there are TV series based on his character (interestingly available in some local American libraries), and there is a Montalbano statue in Camilleri's hometown. One may ask why. Well, Montalbano is a cop with whom one would like to sit and have lunch. Kindhearted, thoughtful, humane, trying to understand people's motives, a caring, and benevolent commentator who hates bureaucracy and paperwork, as we all do. He seems to be Camilleri's alter ego, as Camilleri noted somewhere that Montalbano developed a "life of his own" and, like Camilleri, is well read and familiar with history.

On the first page of Safety Net, the writer A. J. Finn, in his tribute to Camilleri, writes, "You either love Andrea Camilleri or you haven't read him yet." I have probably read about 20 of the Montalbano series books, so I clearly belong to the first group. I agree Camilleri's books are one of the best mysteries around. His books combine good mysteries; Italy, specifically Sicily and its genius loci; dry humor; some wisdom; interesting historical references; keen psychological observations; and great description of good Sicilian food, with Inspector Montalbano being the linchpin of all these things. What else could one wish for in a relaxing mystery reading? For psychiatrists, Montalbano's mysteries provide an entertaining way to ponder psychological contributions to solving crimes and mysteries, to appreciate deductive reasoning, and to better understand the miseries of everyday life.

\section{Compliance with Ethical Standards}

Conflict of interest The author states that there is no conflicts of interest.

\section{Reference}

1. Balon R. Making peace with the past: detective on the couch. Acad Psychiatry. 2015;39:487-8.

Publisher's Note Springer Nature remains neutral with regard to jurisdictional claims in published maps and institutional affiliations. 